flammatory product in the lungs, a clironic pneumonia is said to exist. 'This deposit differs matcrially from those peculiar to the disease which we call tuberculosis. 'The former can remain months and years without lighting up mischief, while in tuberculous disease cavities become formed with the greatest ease. I see, therefore, an important distinction between the two diseases, and it is useless to apply terms in common which may give rise to confusion.

Therefore wo sce that hæmoptysis is not the cause of consecutive disease of the lung; on the contrary, the cause of the pulmonary disease resides elsewhere, and the hromorrhage is only a symptom of a morbid predisposition which subsequently manifests itself under the form of tuberculosis.

Ilæmoptysis likewise proceeds without doubt from other causes, cardiac discase for example. Moreover, certain cascs of hæmoptysis occur independent of disense of the heart, having no connection, indeed, with eventual pulmonary disease, cases in which the hæmorrhage frequently recurs but with no serious pulmonary affection consequent. But such instances are rare, and are sometimes dependent on a tuberculous degeneration limited to a single point in the lung; which, once diseased, never returns perfectly to its normal state, and becomes the seat of hamorrhages which recur from time to time. Other cases also are observed in which the extravasation of blood proceeds solcly from the capillaries or from dilated veins, among which aneurisms by anastomosis are found. Doubtless a metamorphosis of the pulmonary parenchyma can thus give rise to a scrious attack of homoptysis; these attacks may recur, and yet no tuberculosis ever result; when the hæmorrhage ceases, the patient regains his previous health; debility may result, as in other cases of hamorrhage, but farther than this there exists no other symptom worth noting.

CASE OF CIIRONIC ULCER OF THE STOMACII, RESULIING IN PERFORA'TION ANJ) PERITONI'IIS.

Rend before the Norfolk District Medical Society, July 12, 1871, by Gisorgic J. A RNoLn, M.1)., of IRuxbury.

J. W. F., aged 61 years, married; has never been in firm health since having typhoid fever at the age of 25 years. Three and a half years ago he had what was called a bilious attack, commencing as a result of debility, which confined him to his bed for scveral days, and from which he slowly recovered. From this time he suffered ex- ceedingly from pain in region of the stomach a little to the right of the median line, which has been more or less constant. For the past six months he has never, when conscious, been free from it, and at intervals of two or three wecks has been subject to attacks of much greater severity, lasting from 12 to 36 hours, requiring medical treatment. The pain has been of a dull, persistent claracter, without uausea or vomiting; has had dyspepsia. He had come to this city from Asliburnham, on the morning of the 21st of March, 1871, had visited the Statc-house and had done considerable other business during the day, in different parts of the city, and went to the theatre in the evening. 'The day was rainy, and he had made greater exertions than he had been accustomed to; but on returning to lis friend's house at night, he declared he was not much fatigued; he slept well during the night, and expressed himself as much refreshed in the morning; no irregularity in diet was apparent. I learned after his decease that two days previous to coming to Boston he had exerted himself considerably in trying to carry a part of a barrel of apples from the cellar, and had felt a slight injury at the time, but seemed to have recoveres from it cntirely the day following.

At about seven o'clock on the $22 \mathrm{~d}$, he was seized with a severe pain in epignstrium. A homoopath was first called, the case coming to my notice at 12.45 o'clock, P.N. The pain was situated in the epigastrium, just over the pyloric orifice of the stomach, and resembled in virulence and paroxysinal character that occasioned by the passage of a gall-stone. Countenance anxious and distorted with pain; skin warm and natural; pulse 76, full and soft; tongue clean; inclination to nausea; no vomiting. Region of pain had a hatrd feel, and was very sensitive. Bowels soft and pliable. Administered morphia sulphatis half a grain, and in forty minutes, as there was no relicf from pain, it was repeated. Applied chloroform externally, and gave twelve or fifteen drops internally, repeating it at intervals of fifteen minutes, for three or four times. (Strong mustard poultices had been previously applied, by direction of homoopath.) Half past two o'clock, P.M. Pain but slightly relieved; pulse 84 ; perspiring freely ; twenty-five drops fluid extract opium given at three o'clock.

Six o'clock, P.M. Pain still severe, but lessened in violence, still retaining its paroxysmal character; pulse 104. The hard, boardy feel had extended over surface of the bowels as firr as the umbilicus. 
Great tenderness over seat of pain. Some tympanites. Twenty-five drops of fluid extract of opium was given soon after visit, on account of increase of pain.

light o'clock, P.M. I'ain much less; pulse 144, small and weak; great tenderness over whole surface of bowels; tympanites increasing; bowels remarkably firm and unyielding to the touch. Voided urine, about three ounces, by estimation, containing large deposits of urates. Sp. gr. 1020 ; strongly acid.

Half past nine o'clock. Consultation with Dr. Cotting. Symptoms increasing in severity; pulse smaller and weaker. From this time he gradually sank, and died at seven o'clock A.M., of the twenty-third.

Aulopsy by Dr. C. W. Swan, nine hours P.M.-Body emaciated. Rigor considerable. General acute peritonitis. Vivid injection of peritoneum; surfaces of contact of ergans everywhere gently adherent; large masses of soft, yellowish, mucus-like fibrin in hypogastric region; a good deal of brown, muddy, homogeneous liquid of a brothy smell, sponged out from vicinity of stomach. On general inspection, the focus of the discase appeared to be in the region of the pyloric extremity of the stomach.

The lower portion of the stomach was contracted by simple, muscular cffort, into a cylindrical tube, five inches in length, smooth and somewhat flattened externally, while within the mucous membrane was to the same extent thrown into strong longitudinal folds, excepting the lower inch and a half, where the folds were smaller and transverse.

Instead of a distinctly circular pyloric orifice, the parts were irregularly raised into short, heavy folds, projecting somewhat over the duodenum, apparently due, on examination of section, to thickening of the unucous membrane alone, which upon its submucous surface showed an opaque, yellowish white color and papillary form to a degree suggesting a possible state of glandular hypertropliy.

At the lower extremity of the stomach, a little anterior to the line of inner curvature, and almost reaching the origin of the duodenum, was a "chronic ulcer", with a smooth, hard, fibrous base half an inch in diameter, and pretty clearly defined. The general appearunce of the ulcer was angular, from the irregular way in which the folds of mucons meinbranc encountered each other in the vicinity, but these folds were not, pathologically, part of the ulcer, however much they may have been due, as a conservative force, to its indirect influence. Upon the outer anterior side of the base was a rounded perforation of no recent appearance, quarter of an inch in diameter. Externally this orifice was very well defined, smoothly circular, and rather thin edged, apparently from a gradual depression of the surrounding surface towards the opening. In the vicinity adhered some yellow and rather tough fibrin, older than that of the general peritonitis. It was not seen exactly by what this opening had been plugged prior to the occurrence of the acute symptoms. Its position must have been nearly in the angle formed by the left side of the gall-bladder and the adjacent hepatic surface, but it may have been closed by loose omental tissue, as there was nothing like a patch of old fibrin on either of the fixed surfaces mentioned. Upon the opposite side of the pyloric extremity was found the half-concealed base of a second, smaller and unperforated ulcer. 'There were no positive signs of irritation about these ulecis, but there was a slight injection of the minute vessels here, as in varions other parts of the organ. Mucous membrane covered with thick tenacions mucus; healthy, excepting a few small, very superficial losses of substance in the longitudinal folds abovo mentioned. The upper part of the stomach was somewhat distended by gases and contained a light-ycllowish-brown thin fluid, which did not immedialely run from the perforation when the organ was held up to test this point. There was no cicatricial constriction of the pyloric orifice. The liquid found in the vicinity of the stomach resembled the contents, but was darker, as if stained by blood acted upon by gastric juice, and its odor was perceptibly less rank than that of the fluid collected from other parts of the abdominal cavity.

No remarkable distention of intestines. Spleen seven (7) inches long; not onfy quite large, but firm; quite distinct and rather coarse dark and mottling of surface of sections. liver normal; gall-llalder nearly filled with bile, but still flaceid; kidneys rather dark, as from excess of blood, but apparently healthy. No microscopic exnmination. Vrinary bladder somewhat distended.

Lungs healthy. Considerable hypostatic congestion of right lung; left comparatively dry. Upper lobes of both lungs dry. Slight, but not recent pleural adliesion on both sides. Heart: right side distended with blond; no large consula noticed. Slight but evident ligpertiophy of left ventricle, which was in a state of contraction. 
It is thought that no mistake was mado by confounding the thickening of contraction with that which is due to actual hypertrophy, The valves were, in general, a little thickened and opaque, but not, apparently, inefficient. Muscular substance firm.

\section{POISONING BY STRAMONIUM, AND ITS TREA'TMEN'T.}

By D. B. Putva M, M.D., Boston.

Noticing, in a recent number of the Journas, a case of Poisoning by Stramonium, reported by Dr. Stevens, of Charlestown, I will add the result of my experience on the same subject. While in practice for several years in a part of the country where stramonium (Jamestown weed) grows in great abundance as a weed, quite a number of cases of poisoning by this plant came under my treatment.

$\Lambda$ majority of tho cases were those of children who had eaten the secds (for these, by the way, have not a very bad taste), though a few were the result of suicidal intentions on the part of those of an adult age:

When called to a case, in an carly stage of its toxic eflects, I almost invariably found the patient laboring under dizziness, fintness, great distress, and a presentiment of approasching dissolution. Pupils were also found dilated, skin hot, pulse rapid and unsteady, corresponding, inded, to the tilmultuous action of the heart. $\Lambda$ t a later period, the patient would be found in a low inuttering delirium, or with stertorous respiration, great heat of head, cxtreme dilatation of pupils, and a great insensibility to light. It this stage, also, a rash, somewhat resembling urticaria, would make its appearance in proportion to intensity of toxic symptoins.

My treatment of these cases was usually commenced by an emetic, which generally dislodged a lirge quantity of the secds, and then followed by small and frequently-repeated doses of tinct. opii, which never disappointed in its antidotal responses. For, soon the heart's action would show a tendency to return to its normal standard; the stertor and delirium decline; and all the other distressing symptoms subside: the rash and mydriasis acting as a rear guard in the retreat of the array of toxic symptoms. $\Lambda$ s this was severil years aro, and before the antagonistic therapentical action of opium on one side, and stramonium and belladomna, \&c., on the other, was revealed by direct experiment, the use of the former as an antidote to the latter was inferred from their opposite effects on the pupil.

Beforo closing, I will state that, in two cases, I have used stramonium as an antidote to poisoning by opium, and from the promptness and certainty of effect manifested in these cases, I would suggest to the profession a trial of its virtues in cases of this sort.

By this short article, I merely present a sort of resumé of my experience in reference to stramonium, believing it to be the duty of every practitioner to throw something, though it be but a mite, into the treasury of medical information.

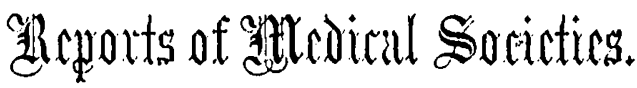

BOSTON SOCIETY FOR MEDICAT, IMPROVEMENT. F. B. GREENOUGIY, SWCRETARY.

IN the last published report of the Society, it should have been stated that the case reported by Dr. Swan, occurred in the practice of Dr. Arnold.

JULY 10th, 1871.- Section of the Ulnar Neree, afler which a Felon on the lillle finger caused no P'ain.-Dr. Ponter exhibited tho patient and reported the case.

$\Lambda$ healthy young man, 22 ycars of ago, 31.2 months ago was stabbed through the fore-arm by some sharp instrument, ho does not know whit. The point cntered upon the inner and posterior aspect near the middle, about an inch inside the inner border of ulna, and came out on the anterior and outer surface, an inch to the radial side of median line. Following the injury thero was complete loss of sensation of the parts of the hand supplied by the ulnar nerve, viz. : both sides of the little finger and the ulnar side of ring finger on the anterior and posterior aspects. It might bo thought that there would be loss of sensation on the contignous sides of the middle and ring fingers posteriorly, but the ulnar before supplying these generally receives a branch from the radial, which would account for the sensation being intact. The paralysis of all tho muscles of the hand supplied by the ulnar could be easily demonstrated. First, The group of special inuscles of the little finger forming the hypothenal eminence he could not contract in the slightest, the palmaris brevis could not be made to corrugate the skin on the nlnar border, as was easily dune on the other hand. S'econd, The muscles of the thenil eminence or ball 